\title{
Indicadores habitacionais brasileiros: análise comparativa da série histórica 1995-2018
}

\author{
Brazilian housing indicators: a comparative \\ analysis of the 1995-2018 time series
}

Rhaiana Bandeira Santana [I] Vanda Alice Garcia Zanoni [II]

\section{Resumo}

Desde 1995, o Brasil publica estudos sobre os indicadores déficit habitacional e inadequação de domicílios a partir do Censo Demográfico e da Pesquisa Nacional de Amostra de Domicílios. Este artigo apresenta uma pesquisa histórica desses indicadores, disponíveis em 13 publicações, com o objetivo de identificar as alterações conceituais e metodológicas ocorridas ao longo da série temporal 19952018. 0 delineamento da pesquisa configura-se em três enfoques: os conceitos envolvidos; a metodologia adotada para a obtenção dos indicadores; e suas métricas e resultados numéricos. A correlação temporal entre as alterações metodológicas, as conceituais e as políticas públicas habitacionais do período revela um panorama das necessidades habitacionais e seus desdobramentos ocorridos ao longo do processo, alertando para as iminentes mudanças no Censo 2020 (com data adiada).

Palavras-chave: necessidades habitacionais; histórico habitacional; indicadores; déficit habitacional; inadequação de domicílios.

\begin{abstract}
Since 1995, Brazil has published studies on housing deficit and housing inadequacy indicators based on the Demographic Census and on the National Household Sample Survey. This paper presents a historical research into these indicators, available in 13 publications, with the objective of identifying the conceptual and methodological changes that occurred throughout the 1995-2018 time series. The research focused on three aspects: the concepts involved; the methodology adopted to obtain the indicators; metrics and numerical results. The temporal correlation between the methodological changes, the conceptual changes and the public housing policies of the period reveals a panorama of housing needs and their consequences throughout this process, alerting to the impending changes in the Brazilian 2020 Census (which has been postponed).
\end{abstract}

Keywords: housing needs; housing history; indicators; housing deficit; housing inadequacy. 


\section{Introdução}

Os indicadores habitacionais proporcionam informações consolidadas que permitem operacionalizar dimensões de interesse em conceitos abstratos, norteando políticas públicas e distribuição de recursos na área habitacional (Januzzi, 2005). O uso desses indicadores pelo governo federal brasileiro vem crescendo no País em todas as suas esferas, e seu interesse, seja a partir de escolhas teóricas ou políticas, está associado ao planejamento para a formulação de políticas públicas, aprimoramento do controle social, elaboração de ferramentas de planejamento e acesso facilitado a informações estruturadas (Januzzi, 2016).

A necessidade de unificação dos indicadores habitacionais surgiu em meados da década de 1990, decorrente das estimativas de déficit habitacional, que variavam entre 6,5 e 15,4 milhões de unidades, com oscilações que chegavam a $200 \%$, a depender da fonte consultada (Taschner, 1992; Caixa, 1992; Cepal, 1993). A grande variação dos dados levou o governo federal brasileiro a buscar parcerias institucionais, visando à criação de um indicador composto capaz de sistematizar e agrupar as informações relacionadas às necessidades habitacionais (Januzzi, 2016). Em dezembro de 1995, por intermédio de convênio celebrado entre a Secretaria de Política Urbana do Ministério do Planejamento e Orçamento e o Programa das Nações Unidas para o Desenvolvimento (Pnud), foi publicado o primeiro estudo da Fundação João Pinheiro sobre o déficit habitacional no Brasil (FJP, 1995).

Na sequência, de 1995 até 2018, foram divulgadas publicações que abarcaram mais de 25 anos de pesquisa sobre as necessidades habitacionais e que vêm sendo utilizadas pelos organismos internacionais, governos nacionais, estaduais e municipais para caracterizar o cenário habitacional brasileiro. Essas publicações apresentam as metodologias e os resultados de pesquisas realizadas no período de 1991 a 2017 e são em número de 13: 12 publicações da Fundação João Pinheiro (FJP) e 1 publicação da Fundação Getúlio Vargas (FGV), cujos dados primários foram fornecidos pelo Instituto Brasileiro de Geografia e Estatística (IBGE) a partir dos levantamentos do Censo Demográfico e da Pesquisa Nacional de Amostra de Domicílios (Pnad).

A publicação da Fundação Getúlio Vargas foi elaborada a pedido da Associação Brasileira de Incorporadoras Imobiliárias (Abrainc), entidade que congrega as 56 maiores incorporadoras do País (Abrainc, 2021). Os resultados publicados mostram uma interrupção de algumas variáveis da série histórica, como a retirada do indicador inadequação de domicílios.

Ademais, desde 2015, os dados da Pnad Anual deixaram de ser publicados e, a partir de 2016, a Pnad Contínua passou a ser a única fonte de dados para o cálculo do déficit habitacional e da inadequação de domicílios. Essa mudança envolveu a exclusão de variáveis importantes para o dimensionamento dos indicadores habitacionais.

Neste artigo, ao investigar as publicações sobre os indicadores déficit habitacional e inadequação de domicílios, objetiva-se analisar os conceitos, as alterações metodológicas, os resultados numéricos desses indicadores e suas relações com as necessidades habitacionais ao longo da série temporal 1995-2018, que utilizou dados primários coletados pelo IBGE no período de 1991 a 2017. Como contribuição, 
considera-se necessário o entendimento das alterações conceituais e metodológicas para a obtenção dos resultados, tendo em vista as iminentes mudanças em decorrência da redução das perguntas para a coleta de dados do Censo 2020, cuja data de realização foi alterada para 2021.

\section{Método}

O delineamento desta pesquisa configura-se em três partes: a) abordagem sobre as mudanças conceituais dos indicadores, seus componentes e subcomponentes, a partir de referenciais teóricos, como Taschner (1992), MagaIhães (2004), Cardoso (2004; 2007) e Januzzi (2005; 2016); b) identificação das alterações na metodologia de dimensionamento das necessidades habitacionais e nas métricas utilizadas; e c) apresentação dos resultados numéricos dos indicadores déficit habitacional e inadequação de domicílios.

Cada um dos indicadores possui componentes e subcomponentes que representam informações das variáveis do IBGE (Pnad ou Censo) determinantes na sua composição. Para identificar as diversas alterações que a metodologia para a obtenção desses indicadores sofreu ao longo da série histórica 1995-2018, buscou-se entender como tais indicadores foram estruturados.

Assim, para a pesquisa documental e bibliográfica, foram investigadas as 13 publicações (Quadro 1), que embasaram as análises dos conceitos, das alterações metodológicas e dos resultados numéricos dos indicadores e suas relações com as necessidades habitacionais.

O Quadro 1 apresenta as publicações da série histórica 1995-2018, identificadas na coluna 1 por meio de números sequenciais. Esses números são utilizados, neste artigo, para referenciar os títulos das respectivas publicações e também os respectivos anos de publicação. No Quadro 1, também são apresentadas as fontes da base de dados e a instituição que elaborou a publicação assim como os anos em que os dados primários foram coletados pelo IBGE (período de 1991 a 2017).

0 conceito dos indicadores habitacionais, desde a primeira publicação (Pub. 1), distingue com clareza os dois macroindicadores que mensuram as necessidades habitacionais: déficit habitacional e inadequação de domicílios. Neste artigo, optou-se por analisar os dois, por entender que ambos se conectam à medida que tanto os aspectos do déficit quanto os da inadequação são tratados por políticas habitacionais.

Para a análise dos resultados, foi utilizada a referência do ano da pesquisa (data da coleta dos dados primários pelo (BGE), que reflete o contexto político e econômico em que foi aplicada. A partir dos resultados do cálculo global do déficit e da inadequação habitacionais, foram analisadas as correlações com as alterações metodológicas e as políticas públicas habitacionais brasileiras vigentes no período, visando a entender o quanto as mudanças metodológicas e conceituais se refletiram nos dados finais dos indicadores e nas possíveis relações com a política habitacional recente. 
Quadro 1 - Listagem das publicações de indicadores de necessidades habitacionais: série 1995-2018

\begin{tabular}{|l|l|c|c|c|c|}
\hline \multicolumn{1}{|c|}{ No } & \multicolumn{1}{|c|}{ Título da publicação } & $\begin{array}{c}\text { Ano da } \\
\text { pesquisa }\end{array}$ & $\begin{array}{c}\text { Ano da } \\
\text { publicação }\end{array}$ & $\begin{array}{c}\text { Base de } \\
\text { dados }\end{array}$ & Instituição \\
\hline Pub.1 & Déficit Habitacional no Brasil & 1991 & 1995 & $\begin{array}{c}\text { Censo } \\
\text { PNAD }\end{array}$ & FJP \\
\hline Pub.2 & Déficit Habitacional no Brasil 2000 & 2000 & 2001 & PNAD & FJP \\
\hline Pub.3 & $\begin{array}{l}\text { Déficit Habitacional no Brasil municípios } \\
\text { selecionados e microrregiões geográficas }\end{array}$ & 2000 & 2004 & Censo & FJP \\
\hline Pub.4 & Déficit Habitacional no Brasil 2005 & 2005 & 2006 & PNAD & FJP \\
\hline Pub.5 & Déficit Habitacional no Brasil 2006 & 2006 & 2008 & PNAD & FJP \\
\hline Pub.6 & Déficit Habitacional no Brasil 2007 & 2007 & 2009 & PNAD & FJP \\
\hline Pub.7 & Déficit Habitacional no Brasil 2008 & $2007-2008$ & 2011 & PNAD & FJP \\
\hline Pub.8 & Déficit Habitacional no Brasil 2009 & 2009 & 2012 & PNAD & FJP \\
\hline Pub.9 & Déficit Habitacional municipal no Brasil 2010 & 2010 & 2013 & Censo & FJP \\
\hline Pub.10 & Déficit Habitacional no Brasil 2011-2012 & $2011-2012$ & 2015 & PNAD & FJP \\
\hline Pub.11 & Déficit Habitacional no Brasil 2013-2014 & $2013-2014$ & 2016 & PNAD & FJP \\
\hline Pub.12 & Déficit Habitacional no Brasil 2015 & 2015 & 2018 & PNAD & FJP \\
\hline Pub.13 & $\begin{array}{l}\text { Análise das necessidades habitacionais e suas } \\
\text { tendências para os próximos dez anos }\end{array}$ & 2017 & 2018 & $\begin{array}{l}\text { PNAD } \\
\text { contínua }\end{array}$ & FGV \\
\hline
\end{tabular}

Fonte: elaborado pelas autoras, a partir de informações da FJP (1995; 2001; 2004; 2006; 2008; 2009; 2011; 2012; 2013 ; 2015; 2016; 2018) e FGV (2018).

\section{Indicador déficit habitacional}

\section{Mudanças conceituais}

Em 1995, o déficit habitacional foi definido como a "noção mais imediata e intuitiva de necessidade de construção de novas moradias para a resolução de problemas sociais detectados em um certo momento e específicos de habitação" (FJP, 1995, p. 6). O cerne do conceito explicitava a necessidade de construção de moradias para a resolução de problemas sociais. Na sua essência, aludia à produção de novas moradias como solução para as deficiências diagnosticadas pelo referido indicador.
Na primeira parte do conceito, a expressão noção mais imediata e intuitiva aparenta certa subjetividade, pois remete a um julgamento súbito, baseado na percepção, independentemente do raciocínio sistêmico ou da análise científica de dados. Já a parte final do conceito - detectados em certo momento e específicos da habitação - reforça a ideia de que o indicador está intrinsecamente relacionado ao tempo e ao espaço em que é mensurado. Nesse sentido, Magalhães (2004) esclarece tratar-se de um evento empírico do mundo real traduzido em dados e acrescido de um valor que, no caso, seria a produção habitacional efetivada a partir de uma teoria ou finalidade programática. 
No período analisado, entre 1995 e 2018, a investigação das 12 publicações da FJP identificou a manutenção da essência do indicador, mas também constatou alterações pontuais e vários deslocamentos conceituais. Acréscimos e mudanças mais significativos ocorreram nas Pub. 3 e Pub. 4, momento em que o conceito ficou mais sintético e foi subdividido, considerando a necessidade de construção de novas moradias, tanto em função da reposição como do incremento do estoque" (FJP, 2004, p. 3).

Nas Pub. 5 e Pub. 9, foram apresentados os conceitos estendidos que incorporavam os termos habitabilidade, coabitação e moradia em imóveis construídos com fins não residenciais. A incorporação desses termos sugere uma ampliação conceitual do que seria o déficit habitacional, agora não relacionado apenas à produção de moradias, mas também à deficiência nas condições de habitabilidade, precariedade construtiva e adequação das famílias à edificação residente.

Na Pub. 5, o déficit habitacional era conceituado como:

[...] ligado diretamente às deficiências do estoque de moradias. Engloba aquelas sem condições de habitabilidade devido à precariedade das construções ou em virtude de terem sofrido desgaste da estrutura física. Essas devem ser repostas. Inclui ainda a necessidade de incremento de estoque, devido à coabitação familiar ou à moradia em imóveis construídos com fins não residenciais. (FJP, 2008, p. 15)

E na Pub. 9:

[...] ligado diretamente às deficiências do estoque de moradias. Engloba aquelas sem condições de serem habitadas em razão da precariedade das construções e que, por isso, devem ser repostas. Inclui ainda a necessidade de incremento do estoque, em função da coabitação familiar forçada (famílias que pretendem constituir um domicílio unifamiliar), dos moradores de baixa renda com dificuldades de pagar aluguel e dos que vivem em casas e apartamentos alugados com grande densidade. Inclui-se ainda nessa rubrica a moradia em imóveis e locais com fins não residenciais. 0 déficit habitacional pode ser entendido, portanto, como déficit por reposição de estoque e déficit por incremento de estoque. (FJP, 2013, p. 13)

Isso significa que as flutuações conceituais que ocorreram nas publicações da Fundação João Pinheiro mantiveram o cerne do conceito, porém com diversas alterações na abordagem global do indicador. Em síntese, essas mudanças não obedeceram a uma evolução temporal clara, pois nelas se identificam momentos em que há regressão a conceitos utilizados e momentos em que há acréscimos conceituais, como nas Pub. 2, Pub. 3, Pub. 4, Pub. 5 e Pub. 9.

A Pub. 12, da Fundação João Pinheiro, ainda considera os dados primários da Pnad 2015, publicada em 2018. Só que, desde então, IBGE mudou a metodologia para Pnad Contínua, com alterações significativas em variáveis utilizadas para mensurar o déficit habitacional.

Concomitantemente à Pub. 12, de 2018, da FJP, a Fundação Getúlio Vargas publicou a Pub. 13, que mensurou o déficit habitacional com adaptação às novas variáveis da Pnad Contínua. Nessa publicação, a FGV alterou o conceito do indicador do déficit habitacional para um "estoque de habitações inexistentes ou inadequadas e deve ser calculado em cada momento do tempo de forma pontual" (FGV, 2018, p. 7). 
Ou seja, observa-se uma mudança significativa no conceito do indicador se comparado ao conceito da FJP. Para a FGV, déficit refere-se a um estoque de moradias que não existem ou que são inadequadas, em contraponto à FJP, que se refere diretamente à necessidade de construção de novas moradias, sem misturá-las com moradias inadequadas. Cabe destacar que a Pub. 13 da FGV não mensura, separadamente, o indicador inadequação de domicílios. Além disso, ao apresentar a expressão deve ser calculado em cada momento do tempo de forma pontual, sua definição vincula os dados do indicador ao número de moradias inadequadas em amostra da população e constatado em um determinado período de medição.

Em síntese, as alterações no conceito de déficit habitacional ao longo do tempo demonstram que a FJP manteve o cerne do indicador durante toda a série histórica, enquanto a FGV mudou radicalmente o conceito, buscando incluir a inadequação de domicílios no conceito de déficit habitacional.

\section{Alterações metodológicas}

O indicador déficit habitacional, em 1995, era composto pelos seguintes componentes e respectivos subcomponentes: precários, que se subdividia em rústicos e improvisados; e coabitação familiar, que se subdividia em conviventes, alugados e cedidos. Já, em 2018, os componentes e respectivos subcomponentes eram: precários, que se subdividiam em rústicos e improvisados; coabitação familiar, que se subdividia em famílias conviventes, alugados, cedidos e próprios; ônus excessivo com o aluguel; e adensamento excessivo em domicílios alugados.
A metodologia para aferir esse indicador sofreu diversas alterações ao longo do tempo. Entre 1995 e 2018, essas várias alterações estão ilustradas no Quadro 2, organizado de acordo com o ano da publicação. Destaque-se que, em vários momentos, os componentes e subcomponentes foram modificados. Um exemplo importante é o subcomponente alugados com ônus maiores que $30 \%$, que deixou de compor a inadequação de domicílios para se transformar em déficit habitacional na Pub. 2. Esse item indica a necessidade de reposição de estoque nos casos em que o grupo familiar gastar mais de $30 \%$ da renda com o aluguel.

Outra mudança na Pub. 2 foi a subdivisão do déficit em duas vertentes: reposição e incremento de estoque. Na reposição, o imóvel deveria ser reconstruído, ao passo que, no incremento, uma nova moradia deveria ser produzida. Na Pub. 1 e a partir da Pub. 4, foram unificados os componentes rústico e improvisado. 0 termo precários passou uma década sem ser utilizado. Não foi encontrada, nas publicações, menção aos motivos dessa unificação.

Houve também um deslocamento conceitual do subcomponente coabitação familiar, resultado da junção entre famílias conviventes secundárias e cômodos alugados ou cedidos. Após a junção, a coabitação familiar tornou-se um componente e um dos que mais sofreram modificações metodológicas na série histórica. Na Pub. 1, o termo usado era famílias conviventes; da Pub. 2 à Pub. 12, converteu-se em coabitação familiar. As publicações de 1 a 3, consoante a componente coabitação, indicavam os dados levantados dos domicílios alugados e cedidos; já, nas Pub. 12 e Pub. 14, tentou-se apresentar dados que justificassem o motivo da coabitação familiar, quando, então, 
apenas as famílias que externaram o desejo de sair da inadequação entraram no cálculo do déficit habitacional.

Dentre os componentes e seus respectivos subcomponentes analisados, destacam-se aqueles subcomponentes que não estão relacionados a nenhum componente (ver Quadro 2): depreciação, alugados urbanos com ônus maiores que $30 \%$, ônus excessivo com aluguel e adensamento excessivo em domicílios alugados.

Os componentes que sofreram alteração com a mudança da Pnad Contínua foram: coabitação familiar e domicílios precários, no subcomponente domicílios improvisados.
A mudança no componente coabitação familiar deve-se à exclusão da estimativa de famílias dos critérios adotados anteriormente pelo IBGE. Por essa razão, deixou de ser possível a estimação direta da coabitação total, passando ela a ser feita a partir do excedente de famílias em relação ao número de domicílios e a partir do pressuposto metodológico de que "o país contaria com pelo menos um domicílio para cada família em média" (FGV, 2018, p. 8). Para o subcomponente domicílios improvisados, foi aplicada uma "proporção histórica recente entre improvisados e coletivos" (ibid., p. 10) e, a partir daí, estimou-se o número de famílias em domicílios improvisados.

Quadro 2 - Mudanças metodológicas no déficit habitacional, na série histórica 1995-2018

\begin{tabular}{|c|c|c|c|c|c|c|c|c|c|c|c|c|c|c|}
\hline \multicolumn{2}{|r|}{ Déficit habitacional } & 1 & 2 & 3 & 4 & 5 & 6 & 7 & 8 & 9 & 10 & 11 & 12 & 13 \\
\hline Componente & Subcomponente & గू & ర్వి & ర్ & ¿ั. & 各 & 오․ & ت্ & 공 & ֻे & กิำ & రั: & $\begin{array}{l}\infty \\
\stackrel{\infty}{2} \\
\text {. }\end{array}$ & స్స \\
\hline \multirow{3}{*}{$\begin{array}{l}\text { Habitações } \\
\text { precárias/ } \\
\text { reposição }\end{array}$} & Rústicos & $x$ & $x$ & $x^{*}$ & & $x$ & $x$ & $x$ & $\mathrm{x}$ & $\mathrm{x}$ & $\mathrm{x}$ & $x$ & $x$ & $x$ \\
\hline & Improvisados & $x$ & $x$ & $x$ & & $\mathrm{x}$ & $x$ & $\mathrm{x}$ & $\mathrm{x}$ & $\mathrm{x}$ & $\mathrm{x}$ & $x$ & $x$ & $x$ \\
\hline & Precários (unificado rústicos e improvisados) & & & & $x$ & & & & & & & & & \\
\hline \multirow{5}{*}{$\begin{array}{l}\text { Coabitação } \\
\text { familiar/ } \\
\text { incremento } \\
\text { do estoque }\end{array}$} & Cômodos alugados, cedidos, próprios & & & & & & & $x$ & $x$ & $\mathrm{x}$ & $\mathrm{x}$ & $x$ & $x$ & \\
\hline & Alugados e cedidos & $x$ & & & & & & & & & & & & \\
\hline & Coabitação & & $x$ & $x^{* *}$ & $x$ & $x$ & $x$ & & & & & & & \\
\hline & Conviventes & $x$ & & & & & & & & & $\mathrm{x}$ & $x$ & $x$ & $x$ \\
\hline & $\begin{array}{l}\text { Famílias conviventes secundárias com intenção } \\
\text { de constituir domicílio exclusivo }\end{array}$ & & & & & & & $x$ & $x$ & $x$ & & & & \\
\hline- & Depreciação & & $\mathrm{x}$ & & & & & & & & & & & \\
\hline- & Alugados urbanos com ônus maiores que $30 \%$ & $x$ & $\mathrm{x}$ & & & & & & & & & & & \\
\hline- & Ônus excessivo com o aluguel & & & & $x$ & $x$ & $x$ & $x$ & $x$ & $\mathrm{x}$ & $\mathrm{x}$ & $x$ & $\mathrm{x}$ & $x$ \\
\hline- & Adensamento excessivo em domicílios alugados & & & & & $x$ & $x$ & $x$ & $x$ & $\mathrm{x}$ & $\mathrm{x}$ & $x$ & $x$ & $x$ \\
\hline
\end{tabular}

Fonte: elaborado pelas autoras a partir das informações da Fundação João Pinheiro (1995; 2001; 2004; 2006; 2008; 2009; 2011; 2012; 2013; 2015; 2016; 2018).

* Metodologia ajustada porque não existia a variável.

**Incluíram-se, no cálculo da coabitação, os cômodos próprios e não somente os alugados e cedidos. 


\section{Resultados numéricos do indicador déficit habitacional}

Em 1991, o déficit habitacional indicava que 4,9 milhões de domicílios deveriam ser produzidos. Em 2005, obteve-se o mais alto déficit, que contabilizou 7,90 milhões. Em 2017, o déficit era de 7,77 milhões. Essa evolução é mostrada na Figura 1, na qual a cor roxa destaca os anos em que ela ultrapassou 7 milhões de unidades habitacionais.

A Figura 2 apresenta o percentual dos subcomponentes do déficit habitacional em relação ao total de domicílios. 0 componente ônus excessivo com o aluguel cresceu gradativamente (componente de cunho econômico), enquanto o componente habitação precária diminuiu também gradativamente - em 1991, eram quase $6 \%$; em 2017, um pouco mais de 1\%. Da mesma forma, a coabitação familiar alcançou, em 2005, mais de $8 \%$ e, em 2017, ficou abaixo de $5 \%$. 0 subcomponente adensamento excessivo em domicílios alugados manteve-se relativamente estável.

0 ônus excessivo com aluguel é um componente de cunho econômico e sua presença no déficit habitacional mantém uma intrínseca relação com a renda das famílias e os gastos com o aluguel, mas não indica, tacitamente, a necessidade de produção de novas unidades, sendo, portanto, passível de questionamento quanto à sua representatividade como componente. Além disso, por ter um peso numericamente alto na composição do indicador, o ônus excessivo com aluguel acaba mascarando os demais componentes e subcomponentes.

Figura 1 - Evolução histórica do déficit habitacional brasileiro do período 1991-2017

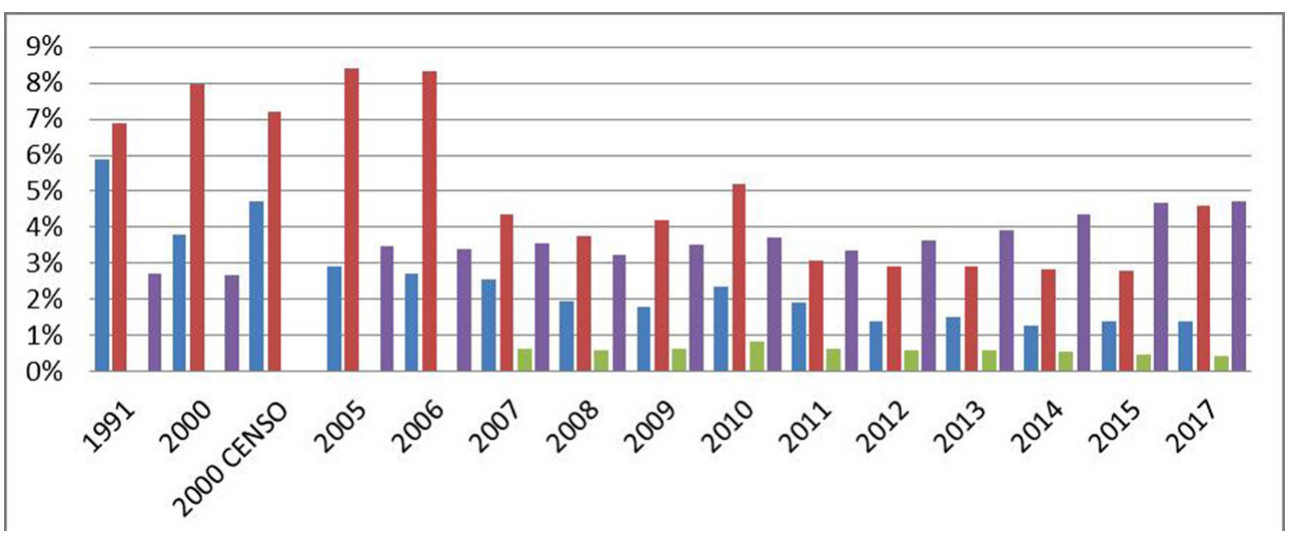

Fonte: elaborado pelas autoras a partir de informações da FJP (1995; 2001; 2004; 2006; 2008; 2009; 2011; 2012; 2013; 2015; 2016; 2018). 
Figura 2 - Proporção entre os componentes e subcomponentes do déficit habitacional brasileiro e o total de domicílios do período 1991-2017

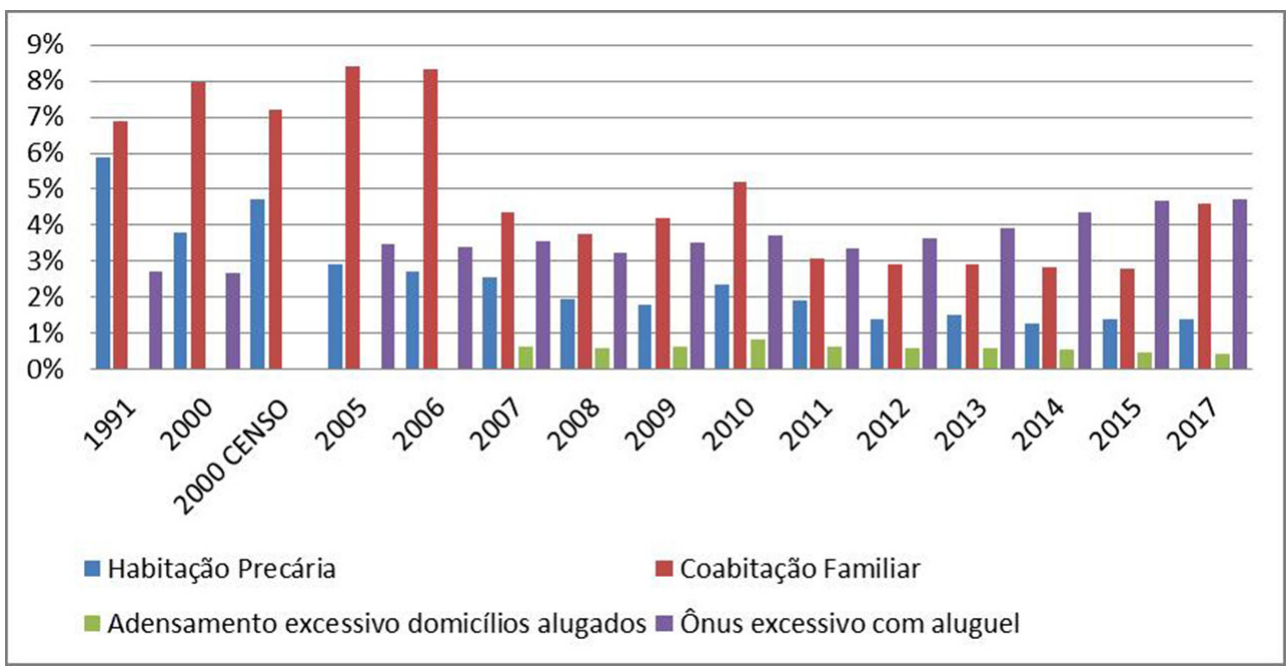

Fonte: elaborado pelas autoras a partir de informações da FJP $(1995 ; 2001 ; 2004 ; 2006 ; 2008 ; 2009 ; 2011 ; 2012$; 2013; 2015; 2016; 2018) e dados primários IBGE (2018).

Além disso, ao analisar os números absolutos do déficit habitacional (Tabela 1), não se observa uma queda muito acentuada no indicador. Porém, ao relacioná-lo com o total de domicílios (relação entre o déficit e a quantidade de domicílios), constatam-se: crescimento entre 1991 e 2000, cujo índice oscilou entre $14 \%$ e $16 \%$, seguido de queda entre 2000 e 2009; estagnação a partir de 2010, quando representou $9 \%$ do total de domicílios brasileiros; e crescimento para $11 \%$ no último levantamento. A estagnação entre 2010 e 2015 pode ser explicada pelo intenso investimento público na área de habitação no período, investimento que não se perpetuou, pois o déficit habitacional voltou a crescer em 2017.
Na Tabela 1, a proporção entre os subcomponentes da metodologia da FJP e da FGV aponta que os componentes habitações precárias, adensamento excessivo em domicílios alugados e ônus excessivo com aluguel apresentam pouca variação entre si, no máximo $0,10 \%$. Entretanto, o subcomponente coabitação, muito modificado metodologicamente, saltou quase $2 \%$ em relação ao ano anterior. Apesar disso, não é possível afirmar se esse aumento se refere apenas à mudança no método, dado que também pode se explicar pela crise econômica e pelo aumento do custo do aluguel e dos imóveis, que podem ter, indiretamente, fomentado o aumento de coabitação no Brasil. 
Tabela 1 - Proporção entre os componentes e subcomponentes do déficit habitacional brasileiro e o total de domicílios do período 1991-2017

\begin{tabular}{lcccccc}
\hline Ano do dado & $\begin{array}{c}\text { Precárias } \\
\text { (em \%) }\end{array}$ & $\begin{array}{c}\text { Coabitacão } \\
\text { (em \%) }\end{array}$ & $\begin{array}{c}\text { Adensamento } \\
\text { excessivo de } \\
\text { domicílios } \\
\text { alugados } \\
\text { (em \%) }\end{array}$ & $\begin{array}{c}\text { Ônus } \\
\text { excessivo } \\
\text { com aluguel } \\
\text { (em \%) }\end{array}$ & $\begin{array}{c}\text { Déficit (\%) / } \\
\text { domicílios }\end{array}$ & $\begin{array}{c}\text { Total de } \\
\text { domićílios } \\
\text { (IBGE }\end{array}$ \\
\hline 1991 & 5,88 & 6,87 & 0 & 2,71 & 14 & 34.881 .250 \\
2000 - PNAD & 3,81 & 7,95 & 0 & 2,69 & 15 & 45.053 .286 \\
2000 - Censo & 4,72 & 7,19 & 0 & 0,00 & 16 & 45.053 .286 \\
2005 & 2,91 & 8,40 & 0 & 3,48 & 15 & 53.417 .000 \\
2006 & 2,73 & 8,34 & 0 & 3,41 & 14 & 54.817 .000 \\
2007 & 2,55 & 4,37 & 0,62 & 3,57 & 11 & 56.448 .000 \\
2008 & 1,95 & 3,74 & 0,58 & 3,24 & 10 & 58.282 .000 \\
2009 & 1,79 & 4,18 & 0,62 & 3,52 & 10 & 59.322 .000 \\
2010 & 2,34 & 5,21 & 0,84 & 3,70 & 12 & 57.428 .017 \\
2011 & 1,91 & 3,08 & 0,62 & 3,36 & 9 & 62.248 .000 \\
2012 & 1,38 & 2,92 & 0,58 & 3,62 & 9 & 63.854 .000 \\
2013 & 1,53 & 2,92 & 0,60 & 3,91 & 9 & 65.258 .000 \\
2014 & 1,29 & 2,85 & 0,55 & 4,36 & 9 & 67.131 .000 \\
2015 & 1,38 & 2,79 & 0,49 & 4,66 & 9 & 68.177 .000 \\
2017 & 1,39 & 4,60 & 0,44 & 4,72 & 11 & 69.773 .385 \\
\hline Média & 2,58 & 5,06 & 0,39 & 3,30 & - & - \\
\hline
\end{tabular}

Fonte: elaborado pelas autoras a partir de informações da FJP $(1995 ; 2001 ; 2004 ; 2006 ; 2008 ; 2009 ; 2011 ; 2012 ; 2013$; 2015; 2016; 2018) e dados primários IBGE (2018).

\section{Indicador inadequação de domicílio}

\section{Mudanças conceituais}

Em 1995, na Pub. 1, o conceito de inadequação de domicílios buscava traduzir, operacionalmente, as dimensões sociais dos problemas na qualidade de vida dos moradores. Como núcleo principal do conceito, não envolvia o dimensionamento do estoque de moradias, mas, sim, as especificidades internas do estoque, no caso habitacional.
[...] reflete problemas na qualidade de vida dos moradores, problemas estes não relacionados, como no primeiro caso [do déficit habitacional], ao dimensionamento do estoque de habitações e suas variações, e sim a especificidades internas de um estoque dado. (FJP, 1995, p. 6)

O conceito de inadequação de domicílios manteve-se relativamente estável durante toda a série histórica, ocorrendo apenas alguns acréscimos conceituais, como nas Pub. 2, Pub. 3 e Pub. 4, quando foi apresentada a questão da habitabilidade - "não proporcionam a seus moradores condições desejáveis de 
habitabilidade, não implicando, contudo, necessidade de construção de novas moradias" (FJP, 2001; 2004; 2006).

Na Pub. 6, quando se comparam os deslocamentos conceituais do déficit e da inadequação, destaca-se que ambos são retomados como os primeiros conceitos citados na série histórica em 1995, o que sugere que foi uma publicação que revisitou conceitos anteriores. E observa-se, novamente, a preocupação de distinguir o conceito de inadequação de domicílios do conceito de déficit habitacional.

Apenas na Pub. 7, em complemento ao conceito apresentado pela FJP, é inserida a seguinte expressão: "Seu dimensionamento visa ao delineamento de políticas complementares à construção de moradias, voltadas para a meIhoria dos domicílios (FJP, 2011). Esse acréscimo conceitual foi utilizado nas Pub. 8, Pub. 10, Pub. 11 e Pub. 12.

Na Pub. 9, é apresentada uma restrição que esclarece que o indicador não mensura inadequações rurais: "Pelo conceito adotado, são passíveis de serem identificadas somente as moradias inadequadas localizadas em áreas urbanas. Não são contempladas as áreas rurais, pois apresentam formas diferenciadas de adequação não captadas pelos dados utilizados" (FJP, 2013). De acordo com o conceito do IBGE utilizado pela FJP, as inadequações domiciliares rurais deviam ser distinguidas das urbanas por possuírem especificidades não medidas pelos dados, como, por exemplo, coleta de lixo, sistema de água e esgoto, entre outros.

Em síntese, na série 1995-2018, observaram-se menos mudanças conceituais no indicador inadequação de domicílios em comparação ao indicador déficit habitacional. Um dos vieses dessa situação pode ser explicado, considerando-se que o conceito de déficit, nos últimos anos, foi amplamente divulgado pelo poder público como justificativa para a intensa produção habitacional. Foram menos expressivas as políticas complementares mensuradas pela inadequação de domicílios, tais como regularização fundiária, melhoria habitacional, saneamento e gestão de resíduos sólidos. Logo, para melhor compreender essas nuances, é relevante explorar as alterações metodológicas desse indicador.

\section{Alterações metodológicas}

O indicador inadequação de domicílios, na Pub. 1, era composto unicamente pelo componente de infraestrutura (subdividido em dois subcomponentes: carente e inadequado), mais os subcomponentes alugados urbanos com ônus maiores que $30 \%$ e adensamento excessivo. Em 2018, a estrutura do indicador passou a ser composta pelo componente: carência de serviços de infraestrutura, que se subdividiu em energia elétrica, abastecimento de água, esgotamento sanitário, coleta seletiva; e pelos subcomponentes: adensamento excessivo de domicílios próprios; inadequação fundiária urbana; inexistência de unidade domiciliar interna; e cobertura inadequada.

Ao observar as alterações metodológicas apresentadas no Quadro 3, percebe-se que a estrutura do indicador inadequação de domicílios sofreu ajustes durante as suas cinco primeiras edições, com a inclusão dos componentes: ausência de banheiro (Pub. 2), inadequação fundiária (Pub. 2) e cobertura inadequada (Pub. 5); e a criação do conceito carência de infraestrutura (Pub. 2). Desde então, não ocorreram alterações metodológicas 
Quadro 3 - Mudanças metodológicas do indicador inadequação de domicílio, na série histórica 1995-2018

\begin{tabular}{|c|c|c|c|c|c|c|c|c|c|c|c|c|c|c|}
\hline \multicolumn{2}{|r|}{ Inadequação de domicílios } & 1 & 2 & 3 & 4 & 5 & 6 & 7 & 8 & 9 & 10 & 11 & 12 & 13 \\
\hline Componente & Subcomponente & ผั & ㅇํำ & ষ্ণ & ััญ & : & : ํํ & กั่ & 근 & กิ่ & กับ & ํํำ & $\stackrel{\infty}{\stackrel{N}{1}}$ & 交 \\
\hline \multirow{2}{*}{ Infraestrutura } & Carente & $x$ & & & & & & & & & & & & - \\
\hline & Inadequada & $x$ & & & & & & & & & & & & - \\
\hline \multirow{4}{*}{$\begin{array}{l}\text { Carência de } \\
\text { serviços de } \\
\text { infraestrutura }\end{array}$} & Energia elétrica & & $x$ & $\mathrm{x}$ & $x$ & $x$ & $x$ & $x$ & $x$ & $x$ & $x$ & $x$ & $x$ & - \\
\hline & Abastecimento de água & & $x$ & $\mathrm{x}$ & $x$ & $\mathrm{x}$ & $\mathrm{x}$ & $x$ & $x$ & $x$ & $x$ & $x$ & $x$ & - \\
\hline & Esgotamento sanitário & & $x$ & $x$ & $x$ & $x$ & $\mathrm{x}$ & $x$ & $x$ & $x$ & $x$ & $x$ & $x$ & - \\
\hline & Coleta seletiva & & $x$ & $x$ & $x$ & $x$ & $\mathrm{x}$ & $x$ & $\mathrm{x}$ & $x$ & $x$ & $x$ & $\mathrm{x}$ & - \\
\hline- & Inadequação em função de depreciação & & $\mathrm{x}$ & & & & & & & & & & & - \\
\hline- & Alugados urbanos com ônus maiores que $30 \%$ & $x$ & & & & & & & & & & & & - \\
\hline- & $\begin{array}{l}\text { Adensamento excessivo (sem distinção entre } \\
\text { alugados e próprios) }\end{array}$ & $x$ & $x$ & $x$ & $\mathrm{x}$ & & & & & & & & & - \\
\hline \multirow{5}{*}{-} & Adensamento excessivo em domicílios próprios & & & & & $x$ & $x$ & $\mathrm{x}$ & $\mathrm{x}$ & $\mathrm{x}$ & $\mathrm{x}$ & $x$ & $\mathrm{x}$ & - \\
\hline & Inadequação fundiária & & $x$ & $x$ & $\mathrm{x}$ & $\mathrm{x}$ & $\mathrm{x}$ & & & & & & & - \\
\hline & Inadequação fundiária urbana & & & & & & & $x$ & $x$ & & $x$ & $x$ & $x$ & - \\
\hline & Inexistência de unidade sanitária interna & & $x$ & $x$ & $\mathrm{x}$ & $\mathrm{x}$ & $\mathrm{x}$ & $x$ & $\mathrm{x}$ & $\mathrm{x}$ & $\mathrm{x}$ & $x$ & $\mathrm{x}$ & - \\
\hline & Cobertura inadequada & & & & & $\mathrm{x}$ & $x$ & $x$ & $x$ & & $x$ & $x$ & $x$ & - \\
\hline
\end{tabular}

Fonte: elaborado pelas autoras, a partir de informações da Fundação João Pinheiro (1995; 2001; 2004; 2006; 2008; $2009 ; 2011 ; 2012 ; 2013 ; 2015 ; 2016 ; 2018)$.

nesse indicador, mantendo-se estável de 2008 até 2018, diferentemente da estrutura do indicador déficit habitacional (Quadro 2), que sofreu ajustes em diversas edições.

A alteração mais substancial realizada na Pub. 2 foi a modificação do subcomponente infraestrutura inadequada para carência de serviços de infraestrutura, que se referia à energia elétrica, ao abastecimento de água, ao esgotamento sanitário e à coleta de lixo. Foram também acrescentados os subcomponentes de inadequação fundiária urbana, inadequação em função da depreciação e inexistência de unidade sanitária domiciliar interna.

\section{Resultados numéricos do indicador inadequação de domicílio}

A respeito da inadequação de domicílios (Figura 3), no primeiro levantamento de 1991, detectaram-se 7,96 milhões de carências; no ano 2000 , chegaram a 20,2 milhões (destacadas na cor roxa, no gráfico), seguidas de uma queda até o último levantamento em 2015, que detectou 11,1 milhões de carências.

A Tabela 2 apresenta o percentual dos subcomponentes de inadequação em relação ao total de domicílios. Observam-se uma queda gradativa do adensamento excessivo em 
Figura 3 - Evolução histórica dos dados de inadequação de domicílios brasileiros do período 1991-2015

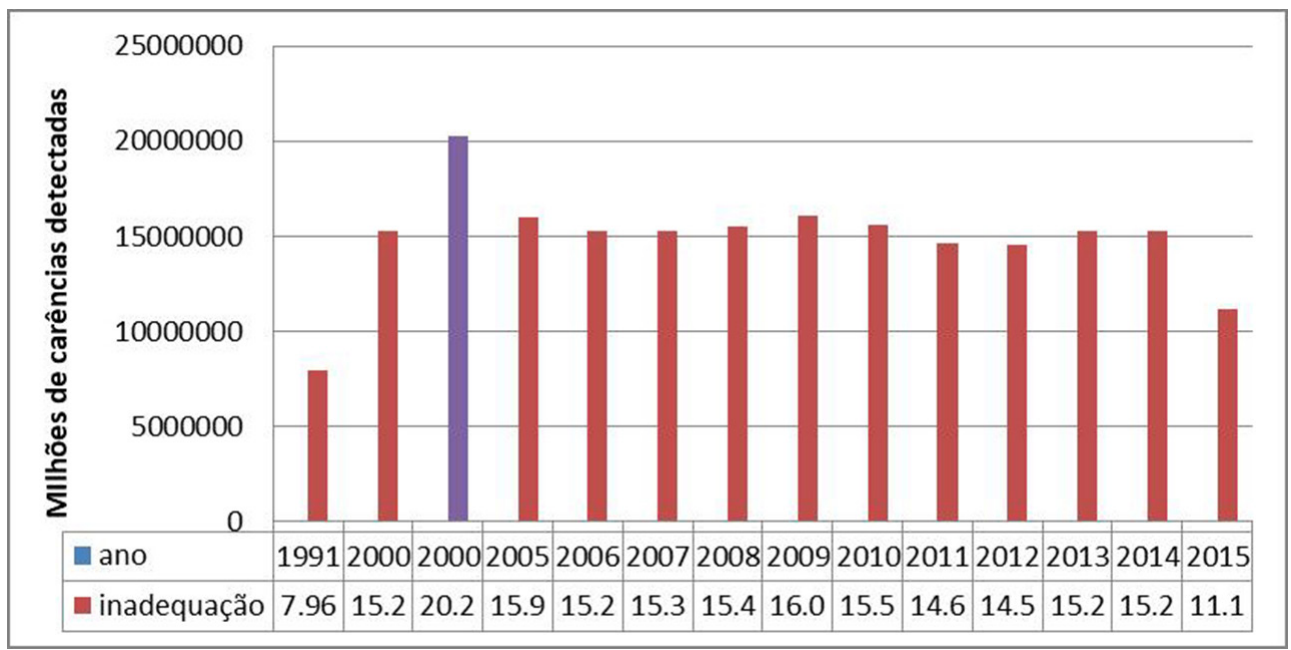

Fonte: Elaborado pelas autoras, a partir de informações da Fundação João Pinheiro (1995; 2001; 2004; 2006; 2008; 2009; 2011; 2012; 2013; 2015; 2016; 2018).

Tabela 2 - Proporção entre os dados coletados para os componentes e subcomponentes de inadequação de domicílios brasileiros e o total de domicílios do período 1991-2017

\begin{tabular}{|c|c|c|c|c|c|c|}
\hline $\begin{array}{c}\text { Ano } \\
\text { do dado }\end{array}$ & $\begin{array}{c}\text { Carência de } \\
\text { infraestrutura } \\
\text { (em \%) }\end{array}$ & $\begin{array}{l}\text { Adensamento } \\
\text { excessivo em } \\
\text { domicílios } \\
\text { próprios } \\
\text { (em \%) }\end{array}$ & $\begin{array}{c}\text { Ausência de } \\
\text { banheiro } \\
\text { (em \%) }\end{array}$ & $\begin{array}{c}\text { Inadequação } \\
\text { fundiária } \\
\text { (em \%) }\end{array}$ & $\begin{array}{c}\text { Cobertura } \\
\text { inadequada } \\
\text { (em \%) }\end{array}$ & $\begin{array}{c}\text { Inadequações } \\
\text { (\%) / } \\
\text { domicílios }\end{array}$ \\
\hline 1991 & 13,99 & 6,12 & - & - & - & 22,83 \\
\hline 2000 - PNAD & 22,78 & 4,49 & 3,26 & 3,35 & - & 33,87 \\
\hline 2000 - Censo & 26,62 & 6,30 & 7,14 & 4,82 & - & 44,88 \\
\hline 2005 & 21,19 & 3,53 & 1,92 & 3,26 & - & 29,90 \\
\hline 2006 & 18,72 & 3,31 & 1,73 & 3,27 & 0,84 & 27,88 \\
\hline 2007 & 18,52 & 2,66 & 1,65 & 3,33 & 0,96 & 27,12 \\
\hline 2008 & 18,79 & 2,46 & 1,37 & 2,90 & 1,03 & 26,55 \\
\hline 2009 & 19,42 & 2,31 & 1,24 & 3,23 & 0,90 & 27,11 \\
\hline 2010 & 22,65 & 2,76 & 1,75 & - & - & 27,16 \\
\hline 2011 & 16,45 & 1,76 & 0,43 & 3,40 & 1,45 & 23,49 \\
\hline 2012 & 16,17 & 1,68 & 0,41 & 3,20 & 1,33 & 22,78 \\
\hline 2013 & 17,00 & 1,56 & 0,32 & 3,02 & 1,45 & 23,34 \\
\hline 2014 & 16,80 & 1,43 & 0,35 & 2,81 & 1,40 & 22,79 \\
\hline 2015 & 10,60 & 1,50 & 0,31 & 2,75 & 1,22 & 16,39 \\
\hline Média & 18,55 & 2,99 & 1,56 & 3,03 & 0,76 & - \\
\hline
\end{tabular}

Fonte: elaborado pelas autoras, a partir de informações da Fundação João Pinheiro (1995; 2001; 2004; 2006; 2008; 2009; 2011; 2012; 2013; 2015; 2016; 2018) e dados primários IBGE (2018).

Nota: O total de domicílios utilizados para os cálculos da Tabela 2 é o mesmo dos dados referenciados na Tabela 1. 
Figura 4 - Proporção entre os componentes de inadequação de domicílios brasileiros e o total de domicílios do período 1991-2017

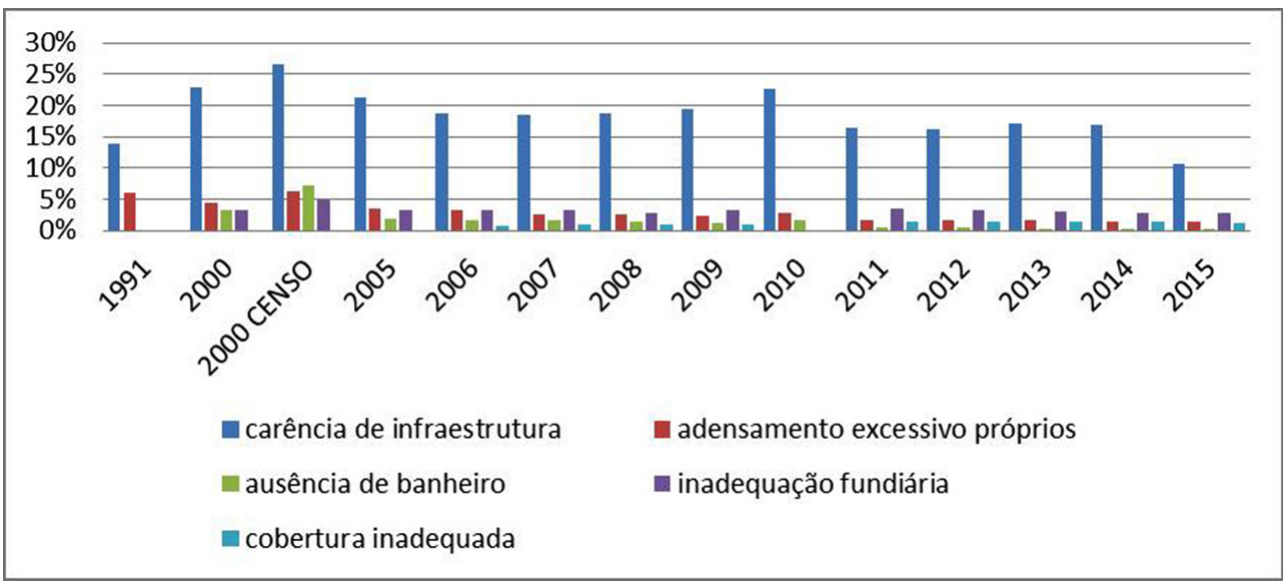

Fonte: elaborado pelas autoras, a partir de informações da FJP (1995; 2001; 2004; 2006; 2008; 2009; 2011; 2012; 2013; 2015; 2016; 2018) e dados primários IBGE (2018).

domicílios próprios, condizente com a queda do adensamento excessivo em domicílios alugados (ver Tabela 1); certa estabilidade na inadequação fundiária; e aumento do percentual de cobertura inadequada. Além disso, destaque-se a preponderância do componente de infraestrutura em relação aos demais, uma vez que, em todas as edições da série 1995-2018, ele constituiu o parâmetro de maior peso do indicador (ver colunas na cor azul na Figura 4).

Destarte, esses resultados apresentados permitem relacionar as mudanças conceituais e metodológicas dos indicadores utilizados nas políticas públicas habitacionais com o dimensionamento dos seus componentes e subcomponentes, traçando um perfil da série histórica de indicadores habitacionais recentes a partir de suas métricas.

\section{Discussões}

Optou-se por discutir a correlação entre as alterações metodológicas e as políticas públicas habitacionais federais do período 1995 a 2018, entendendo que a análise dos resultados dos indicadores pode ser imprecisa, porque o fato de a moradia deixar de ser contabilizada como déficit ou inadequação pode ser explicado por diversos fatores - melhoria de renda familiar, eficácia de políticas públicas locais, melhoria do setor de construção civil, por exemplo não se restringindo, estritamente, a políticas públicas nacionais.

As Pubs. 1 e 2 foram divulgadas no governo Fernando Henrique Cardoso, período de escassez de recursos e expansão limitada 
de investimentos habitacionais devido à forte influência do ajuste fiscal promovido pela adoção do Plano Real (Cardoso, 2007). A partir de 1995, iniciou-se uma reestruturação institucional consistente do setor, momento em que a política habitacional foi regida por diferentes órgãos ao longo do período (ibid, apud Arretche, 1996). Essa reestruturação institucional refletiu-se na tentativa de consolidar, em um único indicador, as informações habitacionais. Verifica-se que, entre a primeira (1995) e a segunda (2001) publicação, foram realizados diversos ajustes, por exemplo, a inclusão dos componentes depreciação, inexistência de unidade sanitária interna, carência de infraestrutura e inadequação fundiária. Essas inclusões sugerem uma preocupação em tornar o indicador habitacional mais consistente e alinhado aos parâmetros internacionais.

As Pubs. 3, 4, 5, e 6 ocorreram no governo Luís Inácio Lula da Silva, em anos de intenso investimento de recursos públicos e estabilidade institucional, período em que a política habitacional esteve sob a gestão do Ministério das Cidades, que se propunha a discutir a temática urbana e a integração das políticas urbanas, utilizando como braço operacional a Caixa Econômica Federal (Maricato, 2006). As Pubs. 3, 4 e 5 apresentam alterações de exclusão, unificação e inclusão de componentes. Os componentes excluídos foram: depreciação, alugados com ônus maiores que $30 \%$ e inadequação em função da depreciação; os incluídos foram: ônus excessivo com aluguel, adensamento excessivo em domicílios alugados e cobertura inadequada; e o componente domicílios precários foi unificado (união de domicílios rústicos e improvisados).
Nesse período, destacam-se dois importantes programas habitacionais federais brasileiros: Programa de Aceleração de Crescimento - Urbanização de Assentamentos Precários (PAC-UAP) e Programa Minha Casa Minha Vida (PMCMV). O PAC-UAP possibilitou a urbanização de áreas, como a Rocinha e o Complexo do Alemão, no Rio de Janeiro; Billings Guarapiranga, em São Paulo; e Bacia do Beberibe, em Recife; a partir do investimento, em todo o País, de $\mathrm{R} \$ 33,5$ bilhões (Brasil, 2014). O MCMV, Iançado em 2009, possibilitou uma produção massiva de unidades habitacionais, ultrapassando o número de unidades produzidas pelo extinto Banco Nacional da Habitação (BNH) e contratando a produção de mais de 6,06 milhões de moradias (Brasil, 2021). Embora isso, esse grande impacto causado na cadeia da construção civil brasileira não se refletiu na redução no indicador déficit habitacional. Essa situação pode ser explicada: $68 \%$ das contratações concentraram-se nas faixas 1,5, 2 e 3 do Programa, faixas que visavam a atender famílias com renda superior a $\mathrm{R} \$ 1.800,00$. Nesse ponto, verifica-se a predominância do componente ônus excessivo com aluguel na composição do indicador.

As Pubs. 7, 8, 9, 10 e 11 ocorreram no governo Dilma, período que manteve a estabilidade institucional, o Ministério das Cidades e nenhuma alteração significativa nos indicadores. Já as Pub. 12 e Pub. 13 aconteceram no governo Temer: a primeira manteve a metodologia dos anos anteriores e a atuação da Fundação João Pinheiro, mas a Pub. 13, do segundo ano, foi realizada pela FGV e, nela, os conceitos de déficit habitacional e inadequação de domicílios foram unificados, além da relevante alteração da Pnad Anual para a Pnad Contínua (FGV, 2018). 
Até meados de 2019, o governo Bolsonaro não havia divulgado qual seria a instituição responsável pela continuidade dos estudos do déficit habitacional e inadequação de domicílios no Brasil. Somente em 2020, após cinco anos de descontinuidade dos dados, a Fundação João Pinheiro foi recontratada pelo governo federal para a atualização dos indicadores para o período 2016-2019 (FJP, 2021a e 2021b).

Em síntese, a Figura 5 mostra, graficamente, que as alterações mais significativas ocorreram nos anos de 2000 e 2018, seguidos dos anos de 2008, 2006 e 2004. Entre 2008 e 2018, a metodologia manteve-se estável, sem grandes alterações, ocorrendo apenas a divulgação das variáveis do IBGE utilizadas nos estudos. A partir de 2013, a divulgação dessas informações possibilita um melhor entendimento da metodologia utilizada, à medida que é possível detectar como é coletado o dado bruto, isto é, a pergunta originária do questionário aplicado pelo IBGE.

As alterações metodológicas possuem correlação com as políticas públicas do período analisado. Cabe destacar que, desde 2008, ocorreram poucas mudanças no indicador inadequação de domicílios (Quadro 3). No entanto, a estrutura do indicador déficit habitacional (Quadro 2) sofreu ajustes em diversas

Figura 5 - Grau de ajuste das alterações metodológicas dos indicadores habitacionais da série histórica 1995-2018

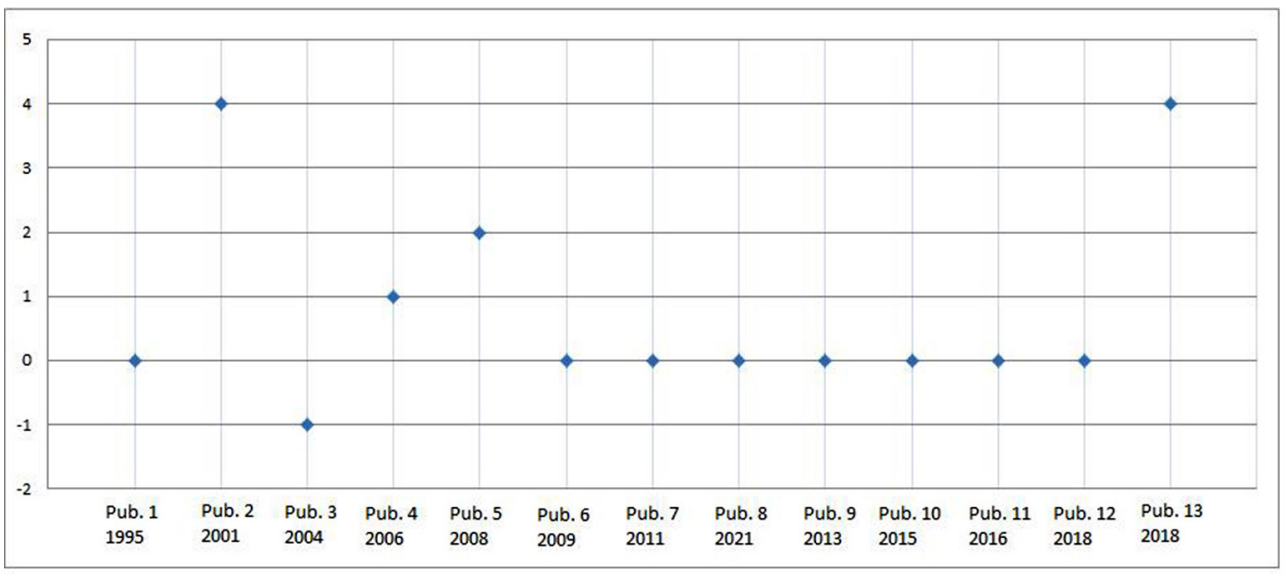

\begin{tabular}{|c|l|}
\hline \multicolumn{2}{|c|}{ Legenda - Figura 5 } \\
\hline Grau de ajuste & \multicolumn{1}{|c|}{ Ajustes } \\
\hline-1 & Exclusão de componentes \\
0 & Estável \\
1 & Unificação de subcomponentes \\
2 & Inclusão de componentes \\
4 & Mudança geral de metodologia \\
\hline
\end{tabular}

Fonte: elaborado pelas autoras, a partir de informações da FJP (1995; 2001; 2004; 2006; 2008; 2009; 2011; 2012; 2013; 2015; 2016; 2018). 
edições. Esse cenário pode ser explicado no pouco uso dado, pelo poder público federal, ao indicador de inadequação e a ênfase no indicador do déficit utilizado como um dos parâmetros de seleção e priorização dentro do Programa Minha Casa Minha Vida (Brasil, 2017 e 2018).

Uma variável pouco abordada nas pesquisas foi a depreciação de domicílios. De acordo com a FJP, a razão pela qual essa depreciação foi quantificada apenas na Pub. 2, tanto no déficit quanto na inadequação, foi a dificuldade de sua quantificação. Isso porque o conceito vincula os domicílios depreciados com a vida útil da edificação, considerando apenas as edificações com mais de 50 anos, sem mensurar o seu estado de conservação. Conforme relatório da Comissão Econômica para a América Latina e o Caribe (Cepal), países latino-americanos, como o Chile e o Uruguai, mensuram a depreciação através de levantamentos de recenseamento (Villatoro, 2017). Por isso, acredita-se que quantificar o componente depreciação no contexto da inadequação dos domicílios brasileiros é uma abordagem a ser equacionada no aprimoramento da metodologia.

As alterações sofridas devido às mudanças nas bases de dados do IBGE, mais especificamente na Pesquisa Nacional por Amostra de Domicílios - Pnad, que passou a considerar a Pnad Contínua, geraram a exclusão de algumas variáveis, resultando na necessidade de adaptações da metodologia do déficit habitacional. Essas adaptações foram realizadas na Pub. 13 pela Fundação Getúlio Vargas, por encomenda da Abrainc. No entanto, nesse estudo da FGV, não foram previstos nem o levantamento, nem o método para o cálculo do indicador inadequação de domicílios.

\section{Considerações finais}

O estudo da série histórica 1995-2018 dos indicadores déficit habitacional e inadequação de domicílios permitiu identificar e analisar as alterações metodológicas e seus desdobramentos, refletindo mais de 25 anos de pesquisas e levantamentos de dados para compor esses indicadores habitacionais. Foi possível apresentar os resultados apurados dos indicadores, seus componentes e subcomponentes, traçando um perfil das mudanças conceituais e metodológicas ocorridas ao longo do processo, associado à análise de conjuntura e às flutuações das necessidades habitacionais.

Embora exista uma multiplicidade de fatores que influenciam esses resultados, sejam eles de cunho conceitual, metodológico, social, econômico ou político, destaca-se a necessidade de se analisar historicamente a evolução dos indicadores habitacionais para fomentar os novos planos e programas habitacionais. Foi possível inferir que as alterações conceituais e metodológicas alinhavam uma correlação temporal com as políticas públicas habitacionais do período e as mudanças institucionais. Os indicadores de déficit habitacional e inadequação de domicílios ainda apresentam carências de detalhamentos conceituais e refinamentos metodológicos, porém exprimem coerência ao longo de toda a sua série histórica.

A mudança da Pnad Anual para a Pnad Contínua exige, inevitavelmente, que alterações sejam feitas. Por essa razão, é preciso atenção para que não se perca a essência do indicador, de forma a garantir que essas mudanças possam efetivamente melhorar a sua representatividade, sem prejuízos substanciais dos resultados. Outras alterações, 
principalmente na coleta dos dados primários, não podem irromper o que vem sendo construído ao longo desse tempo.

Nos últimos anos, pouco se discutiu sobre inadequação de domicílios. Entretanto, é importante dar maior destaque a esse indicador, uma vez que ele é a referência para políticas públicas complementares à produção de novas unidades habitacionais. A aferição desse indicador baliza a desejável e necessária diversificação das ofertas habitacionais, como programas de melhoria habitacional, regularização fundiária, aluguel social, requalificação e reuso de estoques edificados ociosos.

Não obstante as limitações apontadas, pode-se demonstrar que estudos continuados, no caso a série histórica 1995-2018, refletem com maior precisão o diagnóstico habitacional, pois possuem uma carga histórica que nos permite conhecer melhor a trajetória expressa pelo indicador. As recentes mudanças nas variáveis do IBGE e a retirada de importantes perguntas do Censo 2020 podem se tornar indutoras tanto do aperfeiçoamento como da precarização dos indicadores atuais.

Destaque-se, nesse contexto, a problemática gerada pelo adiamento do Censo 2020 para 2021 e pelos cortes orçamentários para a sua execução. Tais fatos podem impactar negativamente a apuração dos indicadores do déficit habitacional e da inadequação de domicílios e, consequentemente, prejudicar a elaboração e o acompanhamento de políticas públicas habitacionais. Por fim, cabe ressaltar a necessidade de discussão da metodologia e a aplicação dos indicadores habitacionais brasileiros em vários níveis e escalas decisórias, inclusive no âmbito das pesquisas acadêmicas e institucionais.

\section{[I] https://orcid.org/0000-0001-8665-6972}

Universidade de Brasília, Faculdade de Arquitetura e Urbanismo, Programa de Pós-Graduação em Arquitetura e Urbanismo. Brasília, DF/Brasil.

rhaiana.bs@gmail.com

\section{[II] https://orcid.org/0000-0003-2629-4214}

Universidade de Brasília, Faculdade de Arquitetura e Urbanismo, Departamento de Tecnologia, Programa de Pós-Graduação em Arquitetura e Urbanismo. Brasília, DF/Brasil.

vandazanoni@unb.br

\section{Nota de agradecimento}

Agradeço ao Programa de Pós-Graduação em Arquitetura e Urbanismo da Universidade de Brasília e à Secretaria Nacional de Habitação do Ministério do Desenvolvimento Regional pelo apoio. 


\section{Referências}

ABRAINC - Associação Brasileira de Incorporadoras Imobiliárias (2021). Quem somos. Disponível em: https://www.abrainc.org.br/institucional/quem-somos/. Acesso em: 2 jul 2021

ARRETCHE, M. (1996). A descentralização como condição de governabilidade: solução ou miragem? Espaço e Debates, n. 16, pp. 75-86.

AZEVEDO, S. de; ARAÚJO, M. B. (2007). Questões metodológicas sobre o déficit habitacional o perigo de abordagens corporativas. Cadernos Metrópole. São Paulo, v. 9, n. 17, pp. 241-255.

BRASIL (2014). Comitê Gestor do Programa de Aceleração do Crescimento. $11^{\circ}$ Balanço PAC2. p. 192. Disponível em: http://www.pac.gov.br/pub/up/pac/11/PAC11_MinhaCasaMinhaVida.pdf. Acesso em: 2 jul 2021.

(2017). Ministério das Cidades. Portaria n. 267, de 22 de março de 2017. Diário Oficial da União. Edição 58, seção 1, p. 111.

(2018). Ministério das Cidades. Portaria n. 367, de 7 de junho de 2018. Diário Oficial da União. Edição 109, seção 1, p. 165.

(2021). Sistema da Habitação. Contratações Minha Casa Minha Vida (2009-2020). Disponível em: http://sishab.mdr.gov.br/. Acesso em: 7 jul 2021.

CAIXA ECONÔMICA FEDERAL (1992). Departamento de Saneamento e Desenvolvimento Urbano. Documento sobre as necessidades habitacionais. Rio de Janeiro.

CARDOSO, A. L. (2004). O déficit habitacional nas metrópoles brasileiras. Indicadores Econômicos FEE. Porto Alegre, v. 32, n. 1, pp. 91-116.

(2007). Política habitacional no Brasil: balanço e perspectivas. Observatório Ippur/UFRJ-Fase.

CEPAL - Comissão Eonômica para a América Latina e o Caribe (1993). América Latina y el caribe: stock de viviendas y estimación de déficit cuantitativo y cualitativo. Santiago, Ilpes.

FGV - Fundação Getulio Vargas (2018). Análise das Necessidades Habitacionais e suas Tendências para os Próximos Dez Anos. Relatório Técnico Final - 2ạ Versão. [s.l.].

FJP - Fundação João Pinheiro (1995). Centro de Estudos Políticos e Sociais. Déficit Habitacional no Brasil - Síntese. Belo Horizonte.

(2001). Centro de Estatística e Informações. Déficit Habitacional no Brasil 2000. Belo Horizonte.

(2004). Centro de Estatística e Informações. Déficit Habitacional no Brasil. Municípios Selecionados e Microrregiões geográficas. Belo Horizonte.

(2006). Centro de Estatística e Informações. Déficit Habitacional no Brasil 2005. Belo Horizonte. (2008). Centro de Estatística e Informações. Déficit Habitacional no Brasil 2006. Belo Horizonte. (2009). Centro de Estatística e Informações. Déficit Habitacional no Brasil 2007. Belo Horizonte. (2011). Centro de Estatística e Informações. Déficit Habitacional no Brasil 2008. Belo Horizonte. (2012). Centro de Estatística e Informações. Déficit Habitacional no Brasil 2009. Belo Horizonte. (2013). Centro de Estatística e Informações. Déficit Habitacional Municipal no Brasil. Belo Horizonte. 
FJP - Fundação João Pinheiro (2015). Centro de Estatística e Informações. Déficit Habitacional no Brasil 2011-2012. Belo Horizonte.

(2016). Centro de Estatística e Informações. Déficit Habitacional no Brasil 2013-2014. Belo Horizonte.

(2018). Centro de Estatística e Informações. Déficit Habitacional no Brasil 2015. Belo Horizonte.

(2021a). Relatório Déficit Habitacional no Brasil 2016-2019. Belo Horizonte.

(2021b). Relatório Inadequação de Domicílios no Brasil 2016-2019. Belo Horizonte.

IBGE - Instituto Brasileiro de Geografia e Estatística (2018). Pesquisa Nacional por Amostra de Domicílios (Pnad). Tabela 1941 - Domicílios particulares e Valor do rendimento médio mensal domiciliar. Disponível em: <https://sidra.ibge.gov.br/tabela/1941>. Acesso em: 14 out 2018.

JANUZZI, P. de M. (2005). Indicadores para diagnóstico, monitoramento e avaliação de programas sociais no Brasil. Revista do Serviço Público, v. 56, n. 2, pp. 137-160. Brasília.

(2016). Indicadores sociais no Brasil: conceitos, fontes de dados e aplicações. Campinas, Alínea.

MAGALHÃES, M. T. Q. (2004). Uma aplicação no planejamento e gestão da política nacional de transportes. Dissertação de mestrado. Brasília, Universidade de Brasília.

MARICATO, E. (2006). O Ministério das Cidades e a Política Nacional de Desenvolvimento Urbano. Ipea - Políticas Sociais - Acompanhamento e Análise, n. 12, pp. 211-220.

TASCHNER, S. P. (1992). O quadro atual da habitação no Brasil: o déficit de moradias como instrumento para avaliação da política habitacional. Revista de Administração Municipal. Rio de Janeiro, v. 39, n. 203 , pp. $48-58$.

VILLATORO, P. (2017). Indicadores no monetarios de carencias en las encuestas de los países de América Latina Disponibilidad, comparabilidad y pertinência. Series de la CEPAL. Estudios estatísticos. Santiago, Chile.

Texto recebido em 10/fev/2021

Texto aprovado em 18/jun/2021 